Article

\title{
Depletion of Alpha-Melanocyte-Stimulating Hormone Induces Insatiable Appetite and Gains in Energy Reserves and Body Weight in Zebrafish
}

\author{
Yang-Wen Hsieh ${ }^{1,2,+}$, Yi-Wen Tsai ${ }^{3,4,+}{ }^{\mathbb{D}}$, Hsin-Hung Lai ${ }^{2}$, Chi-Yu Lai ${ }^{1,2}{ }^{\mathbb{D}}$, Chiu-Ya Lin ${ }^{1,2}$ \\ and Guor Mour Her $2, *$ (iD \\ 1 Department of Bioscience and Biotechnology, National Taiwan Ocean University, Keelung 202, Taiwan; \\ hearhero@hotmail.com (Y.-W.H.); c.y.stephen.lai@gmail.com (C.-Y.L.); vista_jckey_1590@livemail.tw (C.-Y.L.) \\ 2 Institute of Biopharmaceutical Sciences, National Yang Ming Chiao Tung University, Taipei 112, Taiwan; \\ s232579@gmail.com \\ 3 Department of Family Medicine, Chang Gung Memorial Hospital, Keelung 204, Taiwan; \\ tsaiyiwen@gmail.com \\ 4 College of Medicine, Chang Gung University, Taoyuan 333, Taiwan \\ * Correspondence: gmher@nycu.edu.tw; Tel.: +886-2-2826-7000 (ext. 67990) \\ + These authors contributed equally to this work.
}

check for updates

Citation: Hsieh, Y.-W.; Tsai, Y.-W.; Lai, H.-H.; Lai, C.-Y.; Lin, C.-Y.; Her, G.M. Depletion of

Alpha-Melanocyte-Stimulating

Hormone Induces Insatiable Appetite and Gains in Energy Reserves and Body Weight in Zebrafish. Biomedicines 2021, 9, 941. https:// doi.org/10.3390/biomedicines9080941

Academic Editor: James A. Marrs

Received: 28 June 2021

Accepted: 27 July 2021

Published: 2 August 2021

Publisher's Note: MDPI stays neutral with regard to jurisdictional claims in published maps and institutional affiliations.

Copyright: (c) 2021 by the authors. Licensee MDPI, Basel, Switzerland. This article is an open access article distributed under the terms and conditions of the Creative Commons Attribution (CC BY) license (https:// creativecommons.org/licenses/by/ $4.0 /)$
Abstract: The functions of anorexigenic neurons secreting proopiomelanocortin (POMC)/alphamelanocyte-stimulating hormone $(\alpha-\mathrm{MSH})$ of the melanocortin system in the hypothalamus in vertebrates are energy homeostasis, food intake, and body weight regulation. However, the mechanisms remain elusive. This article reports on zebrafish that have been genetically engineered to produce $\alpha$-MSH mutants, $\alpha$-MSH ${ }^{-7 a a}$ and $\alpha-\mathrm{MSH}^{-8 \mathrm{aa}}$, selectively lacking 7 and 8 amino acids within the $\alpha$-MSH region, but retaining most of the other normal melanocortin-signaling (Pomc-derived) peptides. The $\alpha-\mathrm{MSH}$ mutants exhibited hyperphagic phenotypes leading to body weight gain, as observed in human patients and mammalian models. The actions of several genes regulating appetite in zebrafish are similar to those in mammals when analyzed using gene expression analysis. These include four selected orexigenic genes: Promelanin-concentrating hormone ( $p m c h)$, agouti-related protein 2 (agrp2), neuropeptide Y (npy), and hypothalamic hypocretin/orexin (hcrt). We also study five selected anorexigenic genes: Brain-derived neurotrophic factor $(b d n f)$, single-minded homolog 1-a $(\operatorname{sim} 1 a)$, corticotropin-releasing hormone $\mathrm{b}(\mathrm{crhb})$, thyrotropin-releasing hormone $(\mathrm{trh})$, and prohormone convertase 2 (pcsk2). The orexigenic actions of $\alpha$-MSH mutants are rescued completely after hindbrain ventricle injection with a synthetic analog of $\alpha-\mathrm{MSH}$ and a melanocortin receptor agonist, Melanotan II. We evaluate the adverse effects of MSH depletion on energy balance using the Alamar Blue metabolic rate assay. Our results show that $\alpha-\mathrm{MSH}$ is a key regulator of POMC signaling in appetite regulation and energy expenditure, suggesting that it might be a potential therapeutic target for treating human obesity.

Keywords: orexigen; obesogens; adipogenesis; hypothalamus; appetite

\section{Introduction}

The arcuate melanocortin system in vertebrates consists of anorexigenic neurons expressing proopiomelanocortin peptide (POMC), and orexigenic neurons expressing neuropeptide Y/agouti-related peptide (NPY/AgRP). The POMC-expressing neurons of the hypothalamic arcuate nucleus (ARC) participate in the control of food intake, energy homeostasis, body weight (BW) regulation, and other metabolic processes in the melanocortin system [1]. The POMC precursor peptide is processed into a series of biologically active components, including alpha-melanocyte-stimulating hormone $(\alpha-\mathrm{MSH})$, adrenocorticotrophic hormone (ACTH), $\beta$-MSH, and $\beta$-endorphin ( $\beta$-END) by tissue-specific proteolysis $[2,3]$. $\alpha$-MSH functions in anorexigenic responses by activating the melanocortin 
4 receptor (MC4R), which is expressed on distinct second-order neurons, whereas AGRP, the orexigenic peptide, conveys as an antagonist of MC4R [4,5]. In mammals, loss of the genes encoding POMC [6] or MC4R [7,8] leads to severe obesity.

Melanocortin peptides are known to regulate feeding behavior in mammals $[9,10]$. The suppression of appetite in mammals mediated by $\alpha-\mathrm{MSH} / \beta-\mathrm{MSH}$ is attributed to MC4R [7]. In animal models, hyperphagia, an obese phenotype, and hyperinsulinemia were observed in the obese yellow mouse (Ay) model of interruption of $\alpha$-MSH central signaling by the ubiquitous constitutive expression of the agouti gene [11]. Recently, genetically modified Pomc $c^{t m 1 / t m 1}$ mice, which had a mutation in the Pomc gene, were unable to synthesize desacetyl- $\alpha$-MSH and $\alpha$-MSH. Pomc ${ }^{t m 1 / t m 1}$ mice are hyperphagic and show an obese phenotype even when fed a regular chow diet [12,13]. It was recently reported in a model using Labrador retriever dogs that a 14-bp deletion in the gene encoding pro-POMC in these canines is associated with obesity [14]. The $\beta$-MSH [15-17] and $\beta$-endorphin $[18,19]$ coding sequences are also functionally associated with adiposity and greater appetite [20]. In fact, novel mutations (Phe144Leu [21] and Arg145Cys [22]) located in the $\alpha$-MSH domain of the POMC gene were observed to be associated with early-onset obesity.

Additionally, moderately linear growth, which is primarily regulated by growth hormone (GH) released by somatotrophs in the adenohypophysis of the pituitary gland, was also observed in both loss-of-function mutant Pomc or Mc4r rodents and human models [6,7,23-26]. Familial glucocorticoid deficiency (FGD), whose clinical features are enhanced longitudinal bone growth and advanced bone age, is an ACTH-insensitivity disorder characterized by the overproduction of ACTH [27-29].

According to previous studies, Pomc in zebrafish has highly conserved regions similar to ACTH, $\alpha$-MSH, $\beta$-END, $\beta$-MSH, and possibly to N-POMC-derived peptides, but lacks $\gamma$-MSH compared with mammalian models [30]. However, among the two pomc family member genes, pomca and pomcb, observed in zebrafish [2], only pomca, expressed in the pituitary gland, is responsible for developing the interrenal organ of zebrafish [30,31]. In zebrafish, knockdown of the gene encoding Pomca resulted in a significant reduction in Acth immunoreactivity, and attenuated melanosome dispersal at five days postfertilization (dpf) following injection of a designed antisense morpholino oligonucleotide [32]. Shi et al. demonstrated that the increased somatic growth without obesity in pomca mutant zebrafish was associated with reduced anxiety-like behaviors but not with appetite or energy expenditure.

Most research on the biological functions of Pomc in zebrafish focusing on anxiety disorder has been based on the evaluation of changes in Acth expression levels. Here, we used zebrafish to test whether depletion of $\alpha$-MSH signaling might disturb food intake and influence obesity, as the hypothalamic neural circuits involved in food intake are highly conserved in fish species. Our findings provide comprehensive information about the dynamic expression of genes controlling appetite and growth in nonfunctional $\alpha-\mathrm{MSH}$ signaling in the Pomc neurons of zebrafish.

\section{Materials and Methods}

\subsection{Fish Husbandry}

All zebrafish were maintained in a controlled environment with a 14/10-h light-dark cycle at $28{ }^{\circ} \mathrm{C}$. They were fed twice daily with brine shrimp and commercial fish food pellets. All animal experiments were conducted in accordance with the guidelines and approval of the Institutional Animal Care and Use Committee (IACUC) of the National Yang Ming Chiao Tung University, Taiwan.

\subsection{TALEN Cloning and Targeted Mutagenesis}

For each mutant target site in the pomca locus(acc. no. NM_181438.3), two $18 \mathrm{bp}$ TALEN binding sites were selected (exon3: 5'-CCTACTCCATGGAGCAC-3', 5'-CGGTCGGCCGCAAACGC-3'). A restriction enzyme (AgeI) site between each TALEN pair was used for genotyping by restriction fragment length polymorphism (RFLP) analysis. TALEN 
constructs were cloned using Golden Gate assembly (Cermak et al., 2011) and an accompanying plasmid kit from Addgene (Addgene Kit \#1000000024). TALEN mRNAs were injected into 1-cell embryos to generate stable mutant lines. The final TALEN expression plasmids were linearized by digestion with the NotI restriction enzyme. TALEN mRNAs were transcribed using the mMESSAGE SP6 kit (Ambion, USA) and purified using the RNeasy Mini kit (QIAGEN, Hilden, Germany).

\subsection{Quantitative Reverse Transcription Polymerase Chain Reaction (RT-qPCR)}

Total RNA was extracted using TRIzol reagent (Thermo Fisher Scientific, USA) or the RNeasy Mini Kit (QIAGEN, Hilden, Germany) and reverse transcribed using the firststrand cDNA synthesis kit (K1691; Thermo Fisher Scientific). Real-time RT-qPCR was performed using the StepOne Real-Time PCR System (Applied Biosystems, Foster City, USA). The genes and their corresponding primer sequences are listed in Supplementary Table S1. These genes, including those encoding growth hormone $(g h)$, growth hormone receptor $\mathrm{b}(g h r b)$, insulin-like growth factor $2 \mathrm{~b}(i g f 2 b)$, insulin-like growth factor binding protein $1 \mathrm{~b}(\mathrm{igfbp} 1 \mathrm{~b})$, insulin-like growth factor binding protein $5 \mathrm{~b}$ (igfbp5b), and insulin-like growth factor binding protein $6 \mathrm{~b}(i g f b p 6 b)$ have been validated in zebrafish [33].

\subsection{In-Situ Hybridization (ISH)}

The gene-specific probes were cloned by PCR into a pGEM $^{\circledR}$-T Easy TA cloning vector (Promega, Madison, WI USA) using the primers listed in Supplementary Table S2. Antisense probes were synthesized by in vitro transcription using the DIG RNA Labelling Kit (SP6/T7) (Roche Applied Science, Mannheim, Germany). ISH was performed as described previously [34].

\subsection{Quantification of Food Intake}

Our procedure was adapted from that described previously [35]. The larval fish food was fluorescently labeled paramecia prepared using the lipophilic tracer 4-(4(Didecylamino)styryl)-N-Dethylpyridinium iodide (4-Di-10-ASP; Invitrogen, Carlsbad, CA, USA). We conducted feeding of $7 \mathrm{dpf}$ zebrafish in 6-well plates to allow for free swimming. At $1.5 \mathrm{~h}$ after feeding, the larvae were anesthetized. After two washes to remove residual paramecia, groups of five larvae were transferred into a 96-well roundbottom black plate in an anesthetic solution. The intra-abdominal fluorescent signal was measured using the Synergy ${ }^{\mathrm{TM}}$ HT Multi-Detection Reader (BioTek Instruments, Winooski, VT) in fluorescence area scan mode $11 \times 11$ multipoint/well, $0.1 \mathrm{~s} /$ point using a fluorescein filter set (excitation wavelength, $485 \mathrm{~nm}$; emission wavelength, $590 \mathrm{~nm})$.

\subsection{Hindbrain Ventricle Injection of Zebrafish Larvae}

Briefly, anesthetized fish were placed on a $3 \%$ agarose plate with water containing $0.05 \%$ MS222. The skulls were impaled with a $0.53 \mathrm{~mm}$ diameter needle attached to a syringe in the midline at the telencephalon-diencephalon border. The fish were injected intracranially with $4.6 \mathrm{~nL}$ of sterile water, an $\alpha-\mathrm{MSH}$ analog $(100 \mu \mathrm{M}$ in sterile water; M4135, Sigma-Aldrich), or Melanotan II (MTII, $100 \mu \mathrm{M}$ in sterile water; M8693, Sigma-Aldrich) into the cranial cavity by a heat-pulled glass capillary micropipette attached to microinjection equipment. After administration, the cut heads were sampled, and at least 30 larvae were pooled to yield enough total RNA.

\subsection{Histology and Immunohistochemistry (IHC)}

Tissues were fixed using 4\% paraformaldehyde solution in phosphate-buffered saline (PBS) overnight at $4{ }^{\circ} \mathrm{C}$, washed in PBS, and equilibrated in 30\% sucrose/PBS overnight at $4{ }^{\circ} \mathrm{C}$. Then, they were embedded in an OCT compound and cut into $4 \mu \mathrm{m}$ sections using a cryostat. IHC was performed as described previously [36,37]. Rabbit anti- $\alpha$-MSH antibody (1:1000, RayBiotech 130-10355) was used to detect $\alpha$-MSH immunoreactivity. Protein levels 
were detected using horseradish peroxidase (HRP)-conjugated secondary antibody (1:1000, Jackson Immuno Research AB_2313567).

\subsection{Alamar Blue Metabolic Rate Assay}

Our metabolic rate assay was adapted from an established method [38]. The assay buffer was supplemented with egg water containing 0.1\% DMSO, 1\% Alamar Blue (A50101, Thermo Fisher Scientific), and $4 \mathrm{mM}$ sodium bicarbonate. Zebrafish were rinsed with $0.22 \mu \mathrm{m}$ filtered egg water and pipetted into a 96-well plate (three specimens per well). Fluorescence of the plate was immediately read on the Infinite 200 PRO multimode plate reader (Tecan Group Ltd., Switzerland) with excitation at $530 \mathrm{~nm}$ and emission monitored at $590 \mathrm{~nm}$ (fluorescence area scan mode $3 \times 3$ multipoint/well, 10 times/point per reading). The plate was incubated in the dark at $28^{\circ} \mathrm{C}$ for $24 \mathrm{~h}$ and then read again. Any wells containing dead fish were excluded from the analyses. The change in fluorescence from time 0 to $24 \mathrm{~h}$ was then calculated. The data were corrected by setting the average of the wild-type (WT) controls to 1.

\subsection{Whole-Mount Oil Red O Staining}

Zebrafish larvae were fixed in $4 \%$ paraformaldehyde solution in PBS overnight at $4{ }^{\circ} \mathrm{C}$. Equal numbers of control and mutant larvae were transferred to $1.5 \mathrm{~mL}$ Eppendorf tubes and rinsed three times (5 min each) with PBS. After removing the PBS, the larvae were prestained with a mixture of $60 \%$ isopropyl alcohol for at least $1 \mathrm{~h}$. Then, fresh $0.5 \%$ Oil Red $\mathrm{O}$ solution was added at $4{ }^{\circ} \mathrm{C}$ for $1 \mathrm{~h}$, and larvae were washed in PBS. They were stored in 70\% glycerol and imaged using a bright-field dissecting microscope (Stemi 305, Carl Zeiss AG, Oberkochen, Germany).

\subsection{Growth Rate}

The growth rate was recorded monthly starting at two months postfertilization (mpf) and ending at $12 \mathrm{mpf}$. Twenty fish per diet (mixed sex) were selected randomly. Body length (BL) was measured using a standard metric ruler and determined the distance from the snout to the caudal peduncle. BL $(\mathrm{cm})$ and BW $(\mathrm{mg})$ were used to calculate the body mass index (BMI).

\subsection{Morphological and Morphometric Studies: Analysis of Zebrafish Fat Tissues and Adipocytes}

These studies were carried out on histological sections according to Mon-Talbano et al. [39].

\subsection{Statistical Analysis}

All data are presented as the mean \pm standard error of the mean (SEM). Statistical analysis was performed using analysis of variance (ANOVA) followed by Bonferroni posthoc tests. All analyses were performed using GraphPad Prism software (v. 8.0; GraphPad, San Diego, CA, USA). Differences were considered statistically significant at $p<0.05$.

\section{Results}

\subsection{Generation of $\alpha$-MSH Depletion Lines in Zebrafish}

The TALEN-based genome editing technique was performed for the depletion of $\alpha-\mathrm{MSH}$. According to the sequence information, the targeted site of TALENs was located in the third exon of the pomca gene locus. Both arms of the designed binding arms were $18 \mathrm{bp}$ long. The spacer between the two arms was $17 \mathrm{bp}$. The AgeI restriction digestion site within the space region was used for genotyping (Figure 1A). 

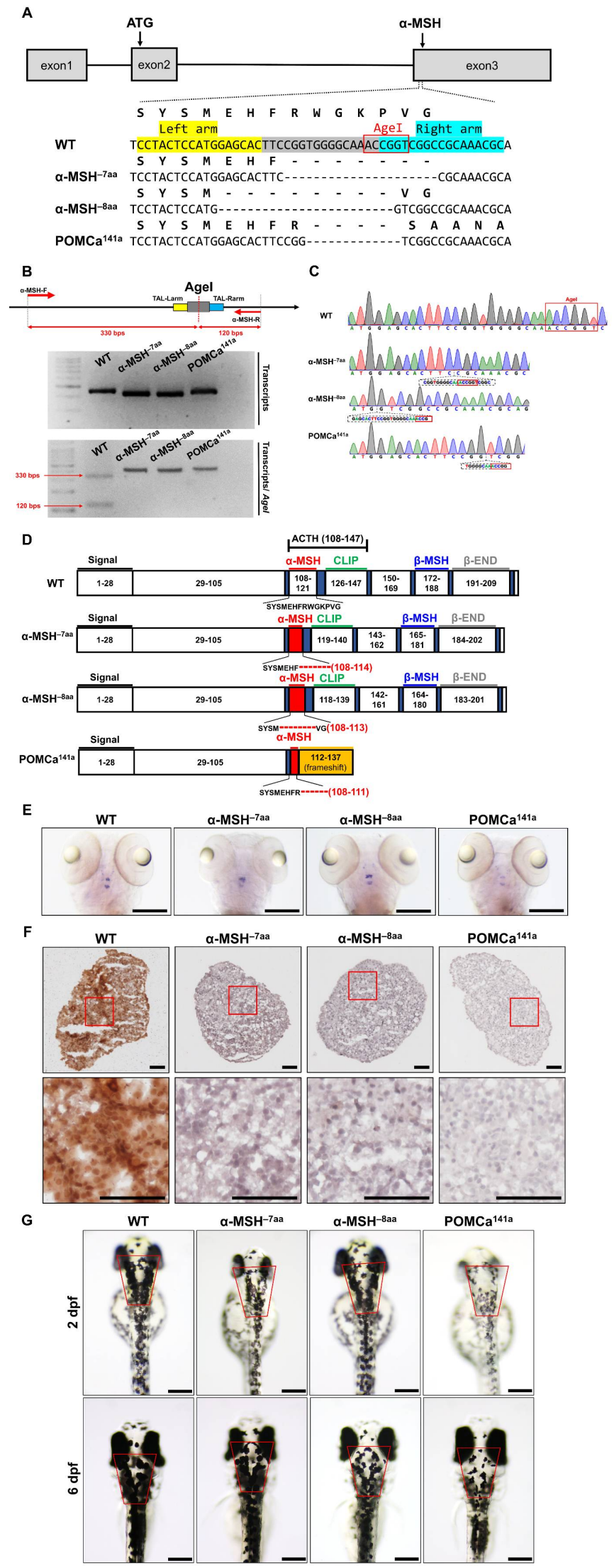

Figure 1. Generation of zebrafish pomca mutants using TALEN. (A) Schematics of the three pomca mutant alleles generated. The sequences in the third exon that were targeted by the TALEN pairs 
are shown in gray boxes. The AgeI restriction enzyme recognition site for genotyping purposes is shown in a red box; dashed lines indicate deleted nucleotides. The left and right TALEN targeting sites are highlighted in yellow and sky blue, respectively. (B) Upper: Schematic illustration of the primers used for RT-qPCR detection of mutations. The specific primer is to the mutated site/scheme of the locations of primers (red arrows) designed to detect a disruption in the spacer of the third exon. Yellow box, left TALEN sites (TAL-L); sky blue box, right TALEN sites (TAL-R); grey box, spacer; red dashed line, AgeI restriction site. Lower: Results of RT-qPCR analyses on fin clips of heterozygous F1 fish containing one of the corresponding mutations (as indicated in A). (C) Chromographs illustrating the sequences in the third exon of the pomca WT controls and the nucleotide deletion of pomca mutants. The boxed sequence in red indicates the restriction enzyme AgeI cutting sites in WT controls that were deleted in the mutant fish. (D) These diagrams show the predicated Pomca protein of pomca mutants compared with the WT Pomca protein. (E) Whole-mount ISH showing the expression of pomca transcripts in the pituitary in WT controls and pomca mutants larvae at $5 \mathrm{dpf}$. Scale bars $=200 \mu \mathrm{m}$. (F) Expression patterns of $\alpha$-MSH in $12 \mathrm{mpf}$ Pomc neuron samples after Immunohistochemistryfrozen section (IHC-F) staining. Scale bar $=50 \mu \mathrm{m}$. (G) Dorsal view of $2 \mathrm{dpf}$ and $6 \mathrm{dpf}$ pomca mutant larvae. Scale bars $=200 \mu \mathrm{m}$.

Three pomca mutants were generated here. Two independent $\alpha$-MSH-depleted mutant lines, $\alpha-\mathrm{MSH}^{-7 \mathrm{aa}}$ and $\alpha-\mathrm{MSH}^{-8 \mathrm{aa}}$ were generated with 21-bp and 24-bp bp in-frame deletions, respectively. One independent pomca mutant line, $\mathrm{POMCa}^{141 \mathrm{a}}$, was generated with a 13-bp frameshift deletion (Figure 1A,B). The $\alpha-\mathrm{MSH}^{-7 \text { aa }}$ and $\alpha-\mathrm{MSH}^{-8 \mathrm{aa}}$ mutations resulted in in-frame deletions that produced truncated proteins of 7 amino acids (aa) and 8 aa within the $\alpha$-MSH regions, respectively (Figure 1C,D). No significantly decreased expression pattern of pomca transcripts was observed in the pituitary gland or hypothalamus of the $\alpha$-MSH mutants, except for the POMCa ${ }^{141 a}$ mutant compared with the WT controls at $5 \mathrm{dpf}$ (Figure 1E). The $\alpha$-MSH mutants caused deficiencies of only the $\alpha-\mathrm{MSH}$ peptide hormones (Figure $1 \mathrm{~F}$ ), whereas the POMCa ${ }^{141 \mathrm{a}}$ mutant resulted in premature stop codons that produced truncated proteins of 141 aa (Figure 1C,D), which caused a deficiency in the majority of melanocortin peptides derived from POMCa (Figure 1F). In addition, three pomca mutants showed attenuated melanosome dispersion in dark conditions, and a significant decrease in melanosomes was observed in the POMCa ${ }^{141 a}$ mutant (Figure 1G).

\subsection{Defective $\alpha-M S H$ Increased Food Intake in Zebrafish}

To evaluate the pattern of food intake at the larval stage of the zebrafish mutants, we used a previously described feeding protocol to prepare fluorescent food composed of larval fish food with lipophilic tracer 4-Di-10-ASP-labeled paramecia [35] (see Methods). The larvae ingested this fluorescent food, which led to an accumulation of fluorescent signals within the intestine that could be visualized readily by fluorescence microscopy (Figure 2A).

The $\alpha-\mathrm{MSH}^{-7 a a}$ and $\alpha-\mathrm{MSH}^{-8 a a}$ larvae exhibited obvious hyperphagia at $7 \mathrm{dpf}$ (Figure 2B), when food intake significantly increased by 2.28-and 2.03-fold, respectively, compared with control WT zebrafish (Figure 2C). However, no obvious differences between POMCa ${ }^{141 a}$ and WT controls were observed in terms of food intake at $7 \mathrm{dpf}$ (data not shown). 
A

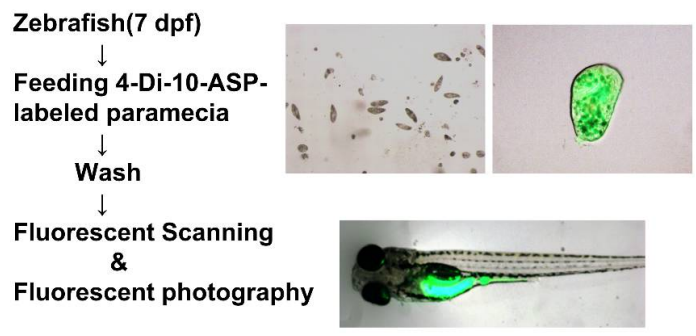

B

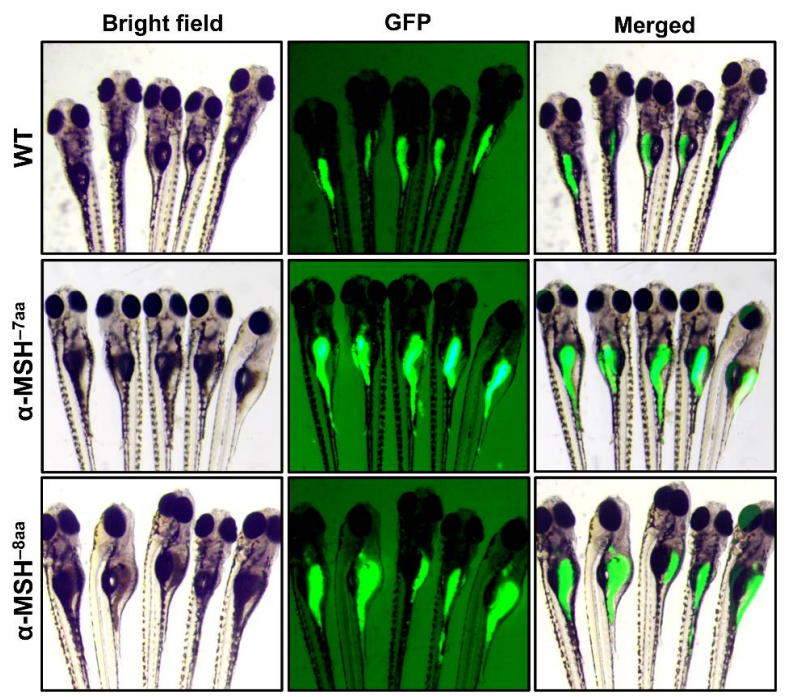

C
HTS paramecium assay

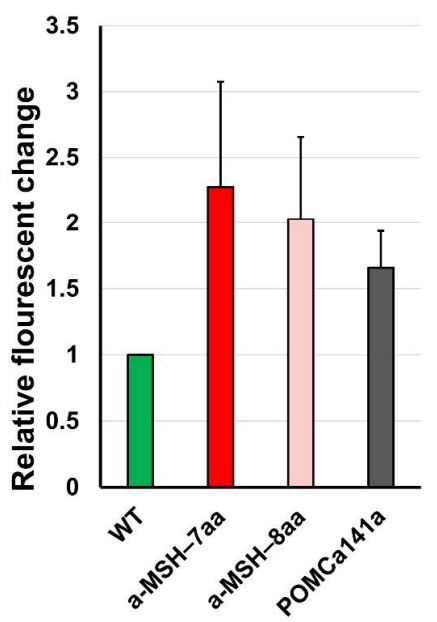

Figure 2. A qualitative food intake assay for zebrafish pomca mutant larvae. (A) Schematic representation of the feeding assay. Fluorescent intensities after free-feeding of 4-10-Di-ASP-labeled paramecia. Fluorescent intensities of ingested paramecia were at maximum levels $1.5 \mathrm{~h}$ after feeding (see Methods). (B) Side views of $7 \mathrm{dpf}$ larvae examined under fluorescence illumination. The larvae were incubated with fluorescent microspheres coated with fish food for up to $1.5 \mathrm{~h}$ before visualizing the fluorescent contents in their gut. (C) Correlation between the relative amount of paramecia and fluorescent intensities of ingested paramecia in zebrafish. The fluorescent intensities were measured from the numbers of introduced paramecia thrice independently. All values are the mean \pm SEM, $n=50$.

\subsection{Defective $\alpha-M S H$ Enhanced Somatic Growth and Decreased Energy Expenditure Concomitant with Liver Steatosis in Zebrafish Larvae}

Next, we tested whether growth and energy budget were proportional to food intake in the POMC mutants, and simultaneous observation was necessary to estimate these parameters. Predictably, the $\alpha$-MSH mutants significantly increased in BL at $8 \mathrm{dpf}$ (Figure 3A). Somatic growth is predominantly controlled by regulating the GH/insulin-like growth factor (IGF) axis in fish [40,41]. Increased mRNA expression of genes controlling the GH/IGF axis accompanied by increased BL was detected in the pomc mutants compared with WT controls at $8 \mathrm{dpf}$ (Figure 3B). Using whole-mount ISH analysis, a significantly increased expression pattern of gh was observed in pomc mutants compared with WT at $5 \mathrm{dpf}$ (Figure $3 \mathrm{C}$ ). Thus, these results indicate that the observed growth activation could be attributed to the upregulation of the GH/IGF axis. 


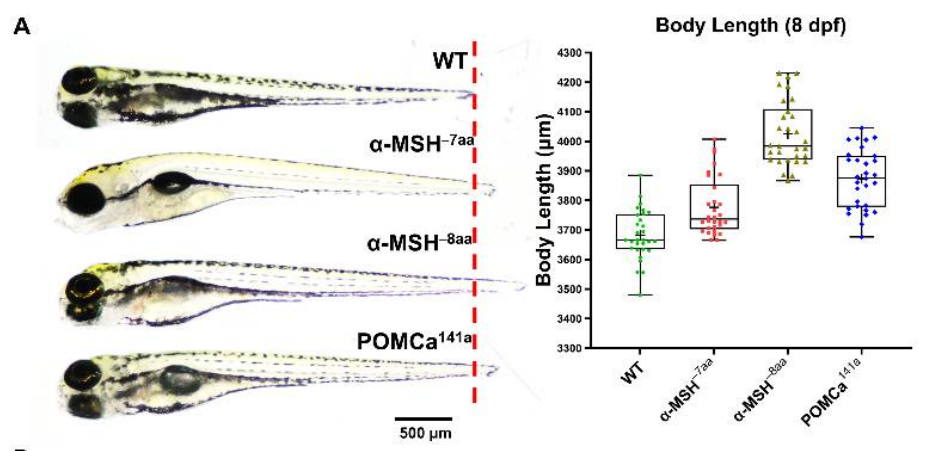

B
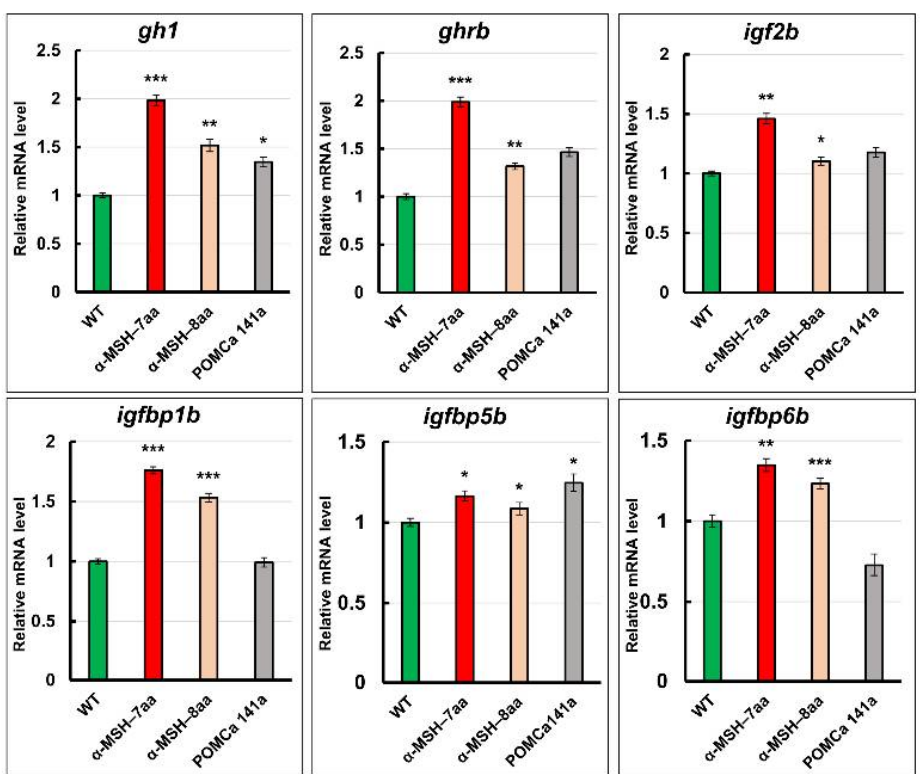

c
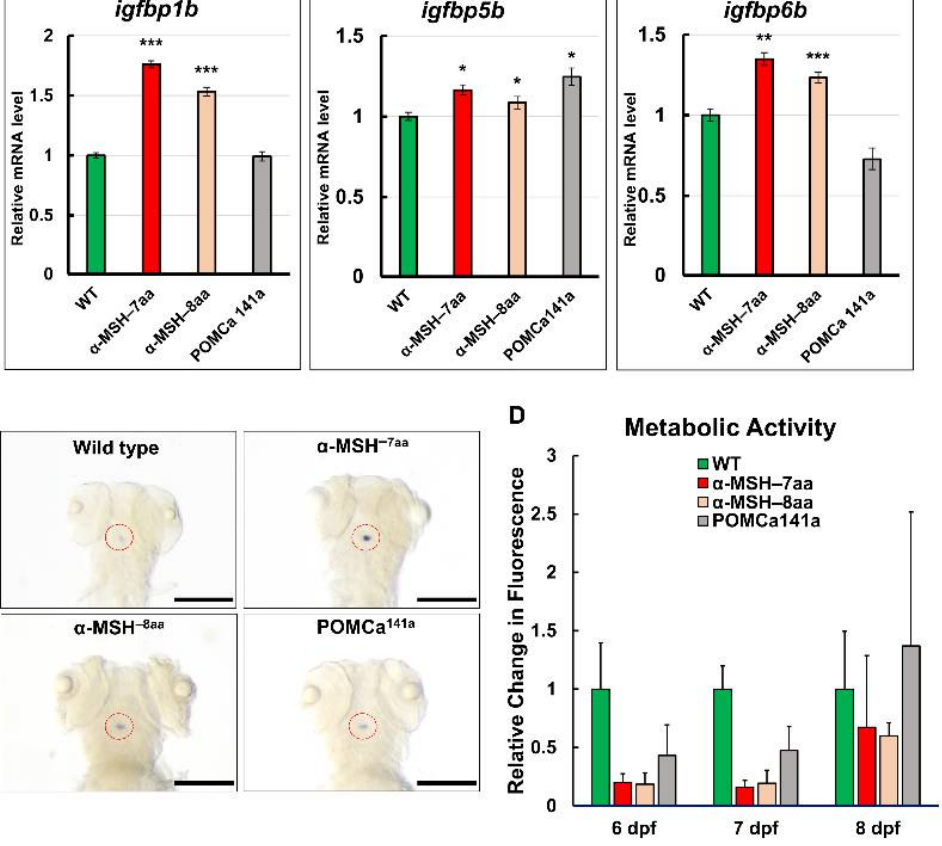

E
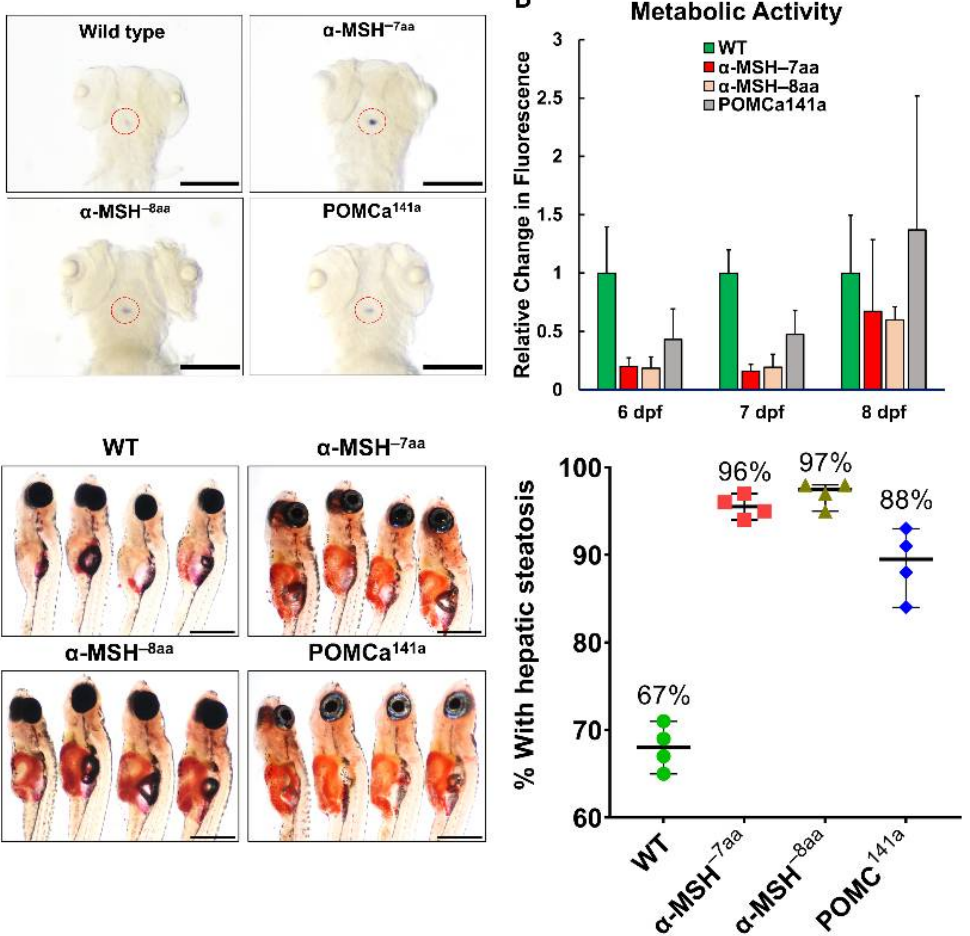

Figure 3. The level of $\alpha$-MSH regulates normal somatic growth and energy balance in zebrafish embryos/larvae. (A) Left: Lateral view of wild-type and pomca mutant larvae at $8 \mathrm{dpf}$. Scale bar $=500 \mu \mathrm{m}$. 
Right: Statistical analysis of BL (jaw to tail fin) in WT controls and pomca mutant larvae at $8 \mathrm{dpf}$. Data are shown as the mean $\pm \mathrm{SD}(n=30)$. (B) Expression of GH/IGF axis genes, gh1, ghrb, igf $2 b$, $i g f b p 1 b$, igfbp $15 b$, and igfbp $6 b$, in WT controls and pomca mutants larvae at $8 \mathrm{dpf}$. Values are the mean \pm SEM. ${ }^{*} p<0.05,{ }^{* *} p<0.01$, and ${ }^{* * *} p<0.001$ compared with WT groups. (C) Whole-mount ISH showing the increased expression of $g h 1$ in the pituitary in pomca mutants larvae at $5 \mathrm{dpf}$. Scale bars $=200 \mu \mathrm{m}$. (D) Response to depletion of $\alpha-\mathrm{MSH}$ in pomca mutant larvae by the Alamar Blue assay. Three larvae per well were incubated in $4 \mathrm{mM}$ sodium bicarbonate with $1 \%$ Alamar Blue. The fluorescence of the solution was measured at different time points. Data are reported as the relative change in fluorescence intensity at least three times independently. (mean \pm SEM, $n=30$ ). (E) Left: Hepatic steatosis was observed by whole-body Oil Red O staining in pomca mutant larvae at 21dpf. Right: Percentages of WT and pomca mutant larvae with strong levels of hepatic steatosis at $21 \mathrm{dpf}$ were calculated from at least 50 fish in each group. Data were representative of four independent experiments. Scale bar $=1 \mathrm{~mm}$.

To assess the potential roles of $\alpha-\mathrm{MSH}$ in the metabolism of the pomc mutants for further studies of energy expenditure that might influence obesity, BW, and appetite regulation, we performed the Alamar Blue metabolic rate assay in larvae at 6-8 dpf. The assay showed increased signals of the zebrafish mutants with incubation time compared with the WT controls (Figure 3D). All pomc mutants larvae exhibited significantly lower metabolic rates, with $53 \%$ to $84 \%$ between the 6 and $7 \mathrm{dpf}$ stages. Both the $\alpha-\mathrm{MSH}^{-7 a a}$ and $\alpha-\mathrm{MSH}^{-8 a a}$ larvae exhibited lower metabolic rates, with decreases of $84 \%$ and $81 \%$, respectively, compared with control WT zebrafish (Figure 3D). However, the POMCa ${ }^{141 a}$ larvae exhibited a slightly higher metabolic rate, with an increase of $37 \%$ compared with control WT zebrafish at $8 \mathrm{dpf}$ (Figure 3D). Furthermore, hepatic steatosis in the $\alpha$-MSH mutants increased markedly compared with that in the WT larvae (Figure 3E), thus confirming that lipid accumulation as an energy reserve is reflected in hepatic steatosis.

\section{4. $\alpha$-MSH Mutant Adults Develop Characteristic Melanocortin-Related Obesity}

Homozygous $\alpha$-MSH mutant larvae developed normally and were slightly larger than the WT larvae (Figure 3A,E). Surprisingly, by measuring the growth rate of POMC mutants and WT zebrafish, a dramatic increase in BL (Figure 4A,B) and BW (Figure 4C) was detected in both $\alpha$-MSH mutant adults compared with WT adults 12 months post-fertilization (mpf). The POMCa ${ }^{141 \mathrm{a}}$ adults showed the same BL as WT adults after $12 \mathrm{mpf}$ and a slight increase in BW compared with WT adults until 9 mpf. (Figure 4C). There were also statistically significant increases in the BMI at $10 \mathrm{mpf}$ for the $\alpha$-MSH mutant adults (Figure 4D).

The BMI showed the same trend observed for BL and BW (Figure 4D). Examination of the BW data showed a significant increase in viscera and visceral fat contents in both the $\alpha-\mathrm{MSH}^{-7 a a}$ and $\alpha-\mathrm{MSH}^{-8 a a}$ groups at the $12 \mathrm{mpf}$ stage (Figure $4 \mathrm{E}$ ). Morphometric analysis of adipose tissues showed a dramatic difference in development between the $\alpha-\mathrm{MSH}$ mutant adults and the WT controls. Both the $\alpha-\mathrm{MSH}^{-7 \text { aa }}$ and $\alpha-\mathrm{MSH}^{-8 \mathrm{aa}}$ adult fish had larger amounts of adipose tissue, with increases of 8- and 12-fold, respectively, compared with control WT zebrafish (Figure 4F,G). Indeed, the average area of both visceral and subcutaneous adipose tissue showed a significant increase in $\alpha$-MSH mutant adults compared with WT controls, indicating that an increase in food intake and decreased energy expenditure determined the growth of an abundant layer of adipose tissue, resulting in obesity. 

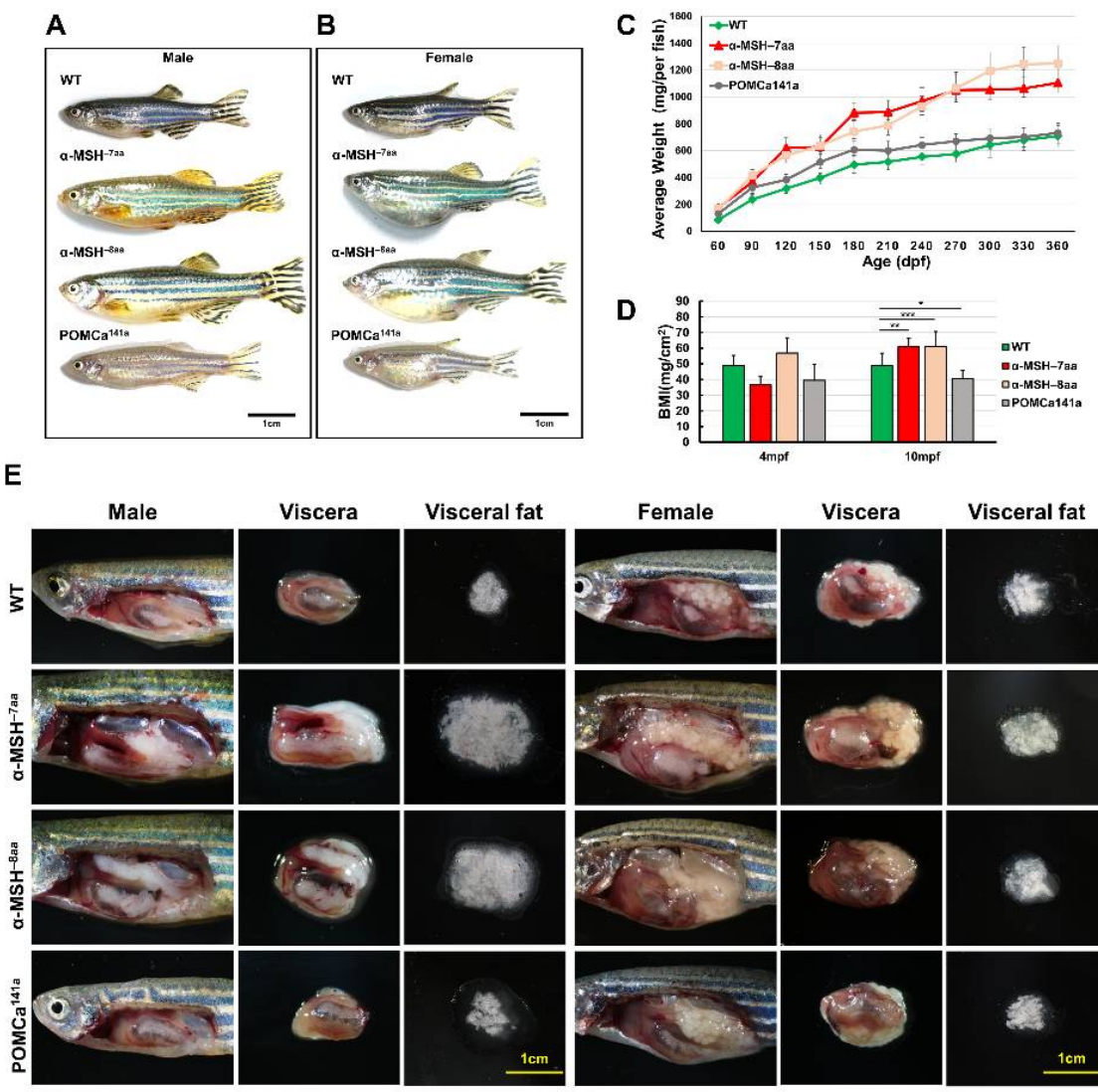

E

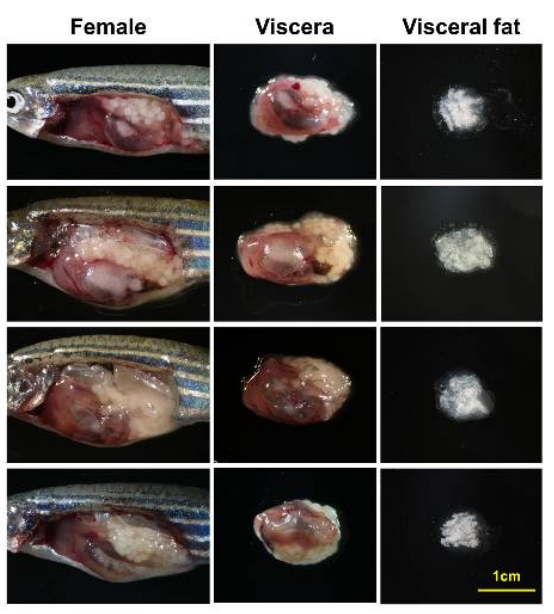

F
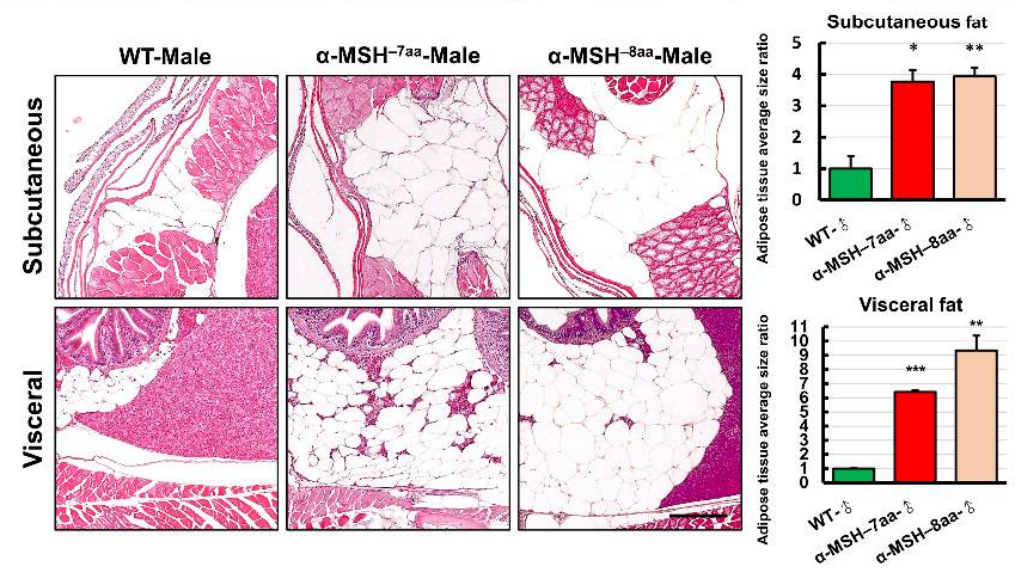

G

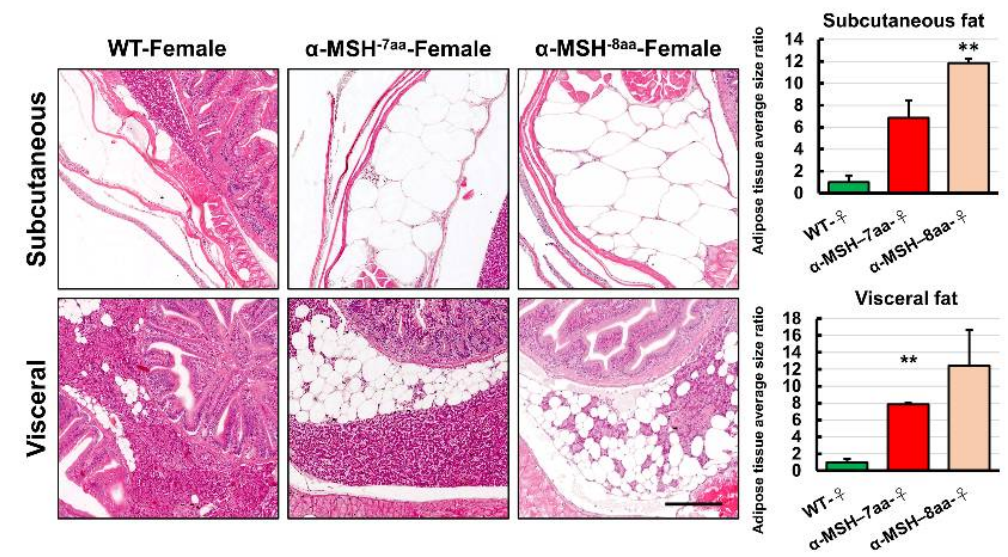

Figure 4. The level of $\alpha$-MSH regulates somatic growth and sexual size dimorphism in pomca mutant adults. (A,B) Lateral view of F2 homozygous male (A) and female (B) mutants compared with WT 
controls at $12 \mathrm{mpf}$. Scale bars $=1 \mathrm{~cm}$. (C) BW curves of zebrafish from the juvenile to adult stages in the three experimental male groups (WT, $\alpha-\mathrm{MSH}^{-7 \mathrm{aa}}$, and $\alpha-\mathrm{MSH}^{-8 \mathrm{aa}} ; n=20$ /group). (D) Bar graph showing the BWs in the three experimental male groups ( $n=20 /$ group) under normal feeding conditions at 4 and $10 \mathrm{mpf}$ stages. (E) Whole mounts of viscera and visceral fat pads in the $\alpha$ $\mathrm{MSH}^{-7 \mathrm{aa}}$ and $\alpha-\mathrm{MSH}^{-8 \mathrm{aa}}$ fish groups at $12 \mathrm{mpf}$, showing increased fat pad size in the $\alpha-\mathrm{MSH}$. $(\mathrm{F}, \mathrm{G})$ Histological features of adipose tissue in hematoxylin and eosin (HE)-stained sagittal sections, showing (F) male and (G) female specimens. Left: HE-stained sagittal sections, showing visceral and subcutaneous adipose tissue contents in the three experimental male groups ( $n=5$ /group). Right: Bar graph showing the body fat volume ratios calculated by morphometric analysis of fat on visceral and subcutaneous adipose tissue average size in each experimental group $(n=5$ in each group). Values are the mean \pm SEM. ${ }^{*} p<0.05,{ }^{* *} p<0.01$, and ${ }^{* *} p<0.001$ compared with WT control groups.

\subsection{Pre-and Postprandial Expression of Appetite-Related Genes in $\alpha$-MSH Mutants}

As several neuronal peptides are involved in regulating food intake and energy balance in zebrafish, as in mammals [42-44], appetite-related gene expression levels were investigated in whole $\alpha$-MSH mutant brains using RT-qPCR. To compare the expression pattern of appetite-related genes between the WT and the pomca mutants, we examined several important factors, including four selected orexigenic genes: Promelanin-concentrating hormone ( $p m c h)$, agouti-related protein 2 (agrp2), neuropeptide Y (npy), and hypothalamic hypocretin/orexin (hcrt) (Figure 5A). We also measured the expression levels of five selected anorexigenic genes: Brain-derived neurotrophic factor $(b d n f)$, single-minded homolog 1a $(\operatorname{sim} 1 a)$, corticotropin-releasing hormone b $(\mathrm{crhb})$, thyrotropin-releasing hormone $(\mathrm{trh})$, and prohormone convertase 2 (pcsk2) (Figure 5B). Although the analyses showed that the orexigenic mRNA levels were slightly downregulated in POMC mutants compared with those in WT controls at $7 \mathrm{dpf}$ (Figure 5A), the anorexigenic mRNA levels were dramatically downregulated in pomca mutants compared with those in WT controls at $7 \mathrm{dpf}$ (Figure 5B). Using whole-mount ISH analysis, significantly decreased expression patterns of $b d n f$ and sim1 a were observed in pomca mutants compared with WT at $5 \mathrm{dpf}$ (Figure 5C). In addition, the intestinal orexigenic gene, ghrelin ( $g h r l)$, was dramatically upregulated in pomca mutants compared with that in WT adults (Figure 5D). Thus, functional $\alpha-\mathrm{MSH}$ signaling is clearly required for transcriptional suppression to some extent of anorexigenic and orexigenic genes and interrupts the balance of hunger and satiety, which in turn possibly increases appetite under normal feeding conditions.

\subsection{Administration of a Synthetic $\alpha-M S H$ Analog Rescued Hyperphagic Phenotypes in $\alpha-M S H$ Mutants}

We investigated whether hindbrain ventricle injections of an $\alpha-\mathrm{MSH}$ analog and MTII into $\alpha$-MSH mutant larvae could reverse the hyperphagic phenotypes (Figure 6A). The feeding evaluation results after the administration of $\alpha-\mathrm{MSH}$ analog (Figure 6B, left) and MTII (Figure 6C, left) were obvious in both the $\alpha-\mathrm{MSH}^{-7 \mathrm{aa}}$ and $\alpha-\mathrm{MSH}^{-8 \mathrm{aa}}$ specimens at $7 \mathrm{dpf}$, respectively. Both $\alpha-\mathrm{MSH}^{-7 \mathrm{aa}}$ and $\alpha-\mathrm{MSH}^{-8 \mathrm{aa}}$ fish could be rescued by the $\alpha-\mathrm{MSH}$ analog and MTII-similar to normal phenotypes-although their anorexigenic effects were stronger than in WT controls (Figure 6B,C).

To clarify whether the appetite-related gene expression levels were modulated directly by administration of the $\alpha$-MSH analog in $\alpha$-MSH mutant larvae, the mRNA levels of the orexigenic genes npy, agrp2, and hcrt were significantly lower than the mRNA levels of the anorexigenic genes $b d n f, \operatorname{sim} 1 a, c h r b$, and trh at $1.5 \mathrm{~h}$ after intracranial administration compared with the $\alpha$-MSH mutant larvae (Figure 6D,E). 
A

\section{Orexigenic Gene-Brain}

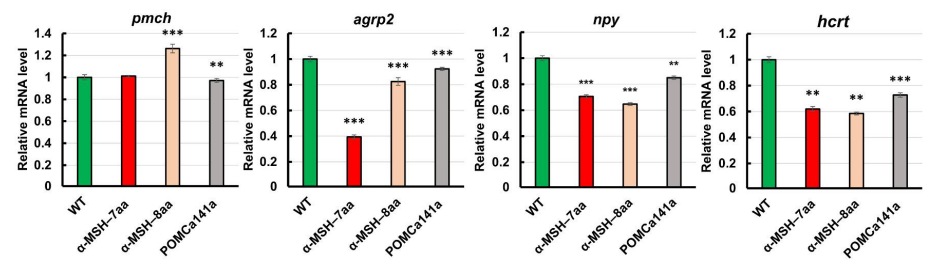

B

Anorexigenic Gene-Brain
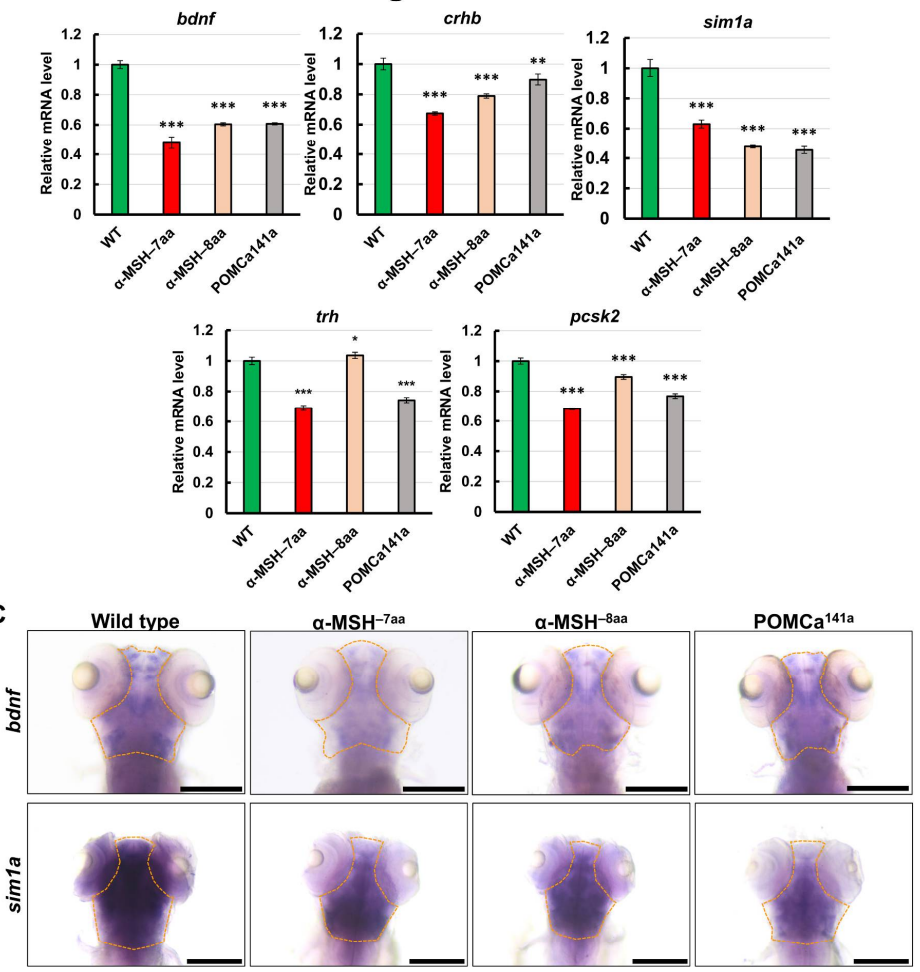

D Orexigenic Gene-Intestinal

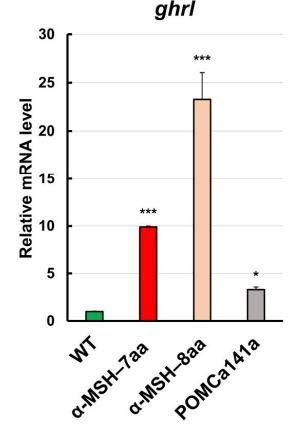

Figure 5. Effects of $\alpha$-MSH on feeding regulation in the hypothalamus of zebrafish. (A,B) RT-qPCR analysis was used to measure the mRNA levels of four selected orexigenic genes, pmch, agrp2, npy, and $h c r t(\mathbf{A})$, and five selected anorexigenic genes, $b d n f$, sim $1 a, c r h b$, trh, and $p c s k 2(\mathbf{B})$ in the WT and pomca mutants at $1.5 \mathrm{~h}$ after feeding. (C) Whole-mount ISH showing decreased expression of $b d n f$ and sim $1 a$ in the pituitary in WT and pomca mutant larvae at $5 \mathrm{dpf}$. Scale bars, $200 \mu \mathrm{m}$. (D) RT-qPCR analysis was used to measure the mRNA level of the intestinal orexigenic gene, ghrl, in WT and pomca mutant adults. Values are means \pm SEM. ${ }^{*} p<0.05,{ }^{* *} p<0.01$, and ${ }^{* * *} p<0.001$ compared with WT control groups. 


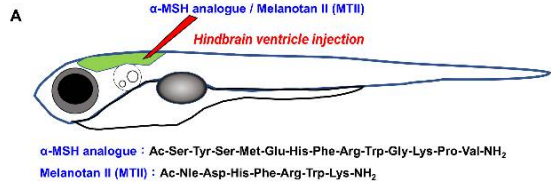

B
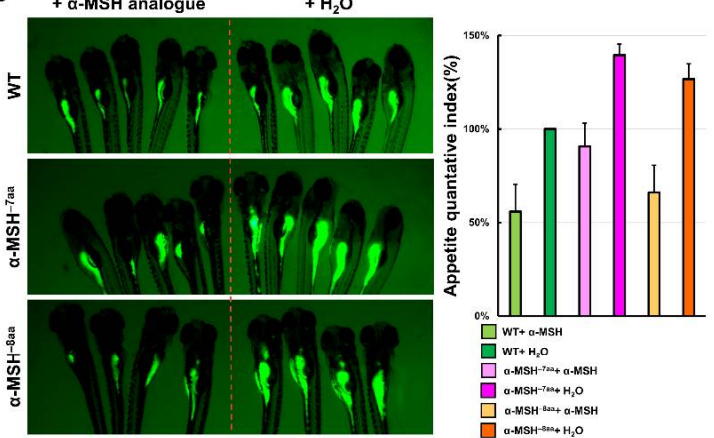

$\square \mathrm{WT+ \alpha -MSH}$

a.MSH-Tima a-MSH

$a^{\mathrm{a} \cdot \mathrm{NSH}-\mathrm{Tas}+\mathrm{H}_{\mathrm{H}} \mathrm{O}}$

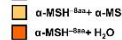
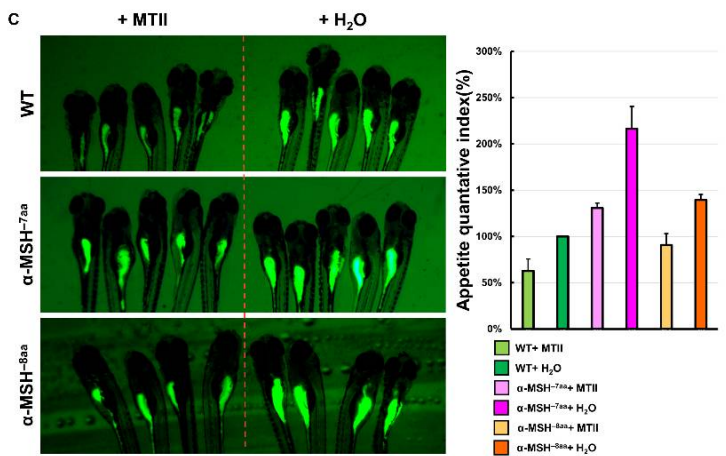
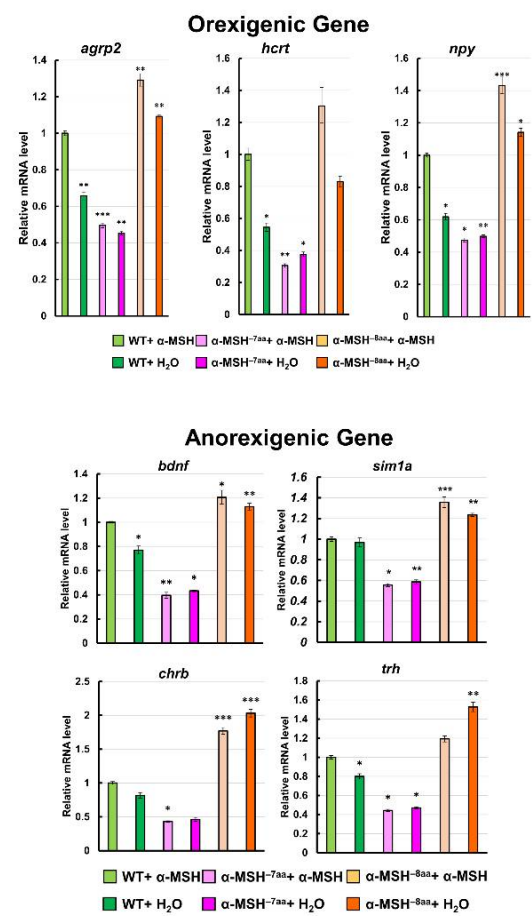

Figure 6. Effects of a synthetic $\alpha$-MSH analog in rescuing hyperphagic phenotypes in $\alpha$-MSH mutant larvae. (A) Schematic representation of hindbrain ventricle injection of an $\alpha-\mathrm{MSH}$ analog/MTII into $\alpha$-MSH mutant larvae. (B) $\alpha$-MSH analog, and (C) MTII. Left: Administration decreased feeding volume in $\alpha-\mathrm{MSH}$ mutant larvae at $7 \mathrm{dpf}$. Right: Bar graph showing the quantified appetite levels measured by morphometric analysis of fluorescent intensities in each experimental group (WT, $\alpha-\mathrm{MSH}^{-7 \mathrm{aa}}$, and $\left.\alpha-\mathrm{MSH}^{-8 \mathrm{aa}}\right)\left(n=50\right.$ /group). Values are means $\pm \mathrm{SEM}^{*} p<0.05,{ }^{* *} p<0.01$, and *** $p<0.001$ compared with WT groups. (D,E) RT-qPCR analysis was used to measure the mRNA levels of three selected orexigenic genes, agrp2, npy, and hcrt (D), and four selected anorexigenic genes, $b d n f, \operatorname{sim} 1 a, c r h b$, and $\operatorname{trh}(\mathrm{E})$ in the WT and $\alpha-\mathrm{MSH}$ mutant larvae at $1.5 \mathrm{~h}$ after feeding. We used relative fluorescent change and relative transcriptome expression for quantification three times $(n=50)$ independently.

\section{Discussion}

MSHs are well-known feeding and camouflage behavior-regulated hormones in mammals (Yaswen et al., 1999; Raffan et al., 2016). MC4R is a key gene controlling the $\alpha-\mathrm{MSH}-$ mediated suppression of appetite in mammals $[4,7,15,17,45]$. Intracerebroventricular (icv) or intraperitoneal (ip) injection of MC4R agonists can suppress food intake in goldfish [46], zebrafish [47], spotted sea bass [48], and coho salmon [49], while transgenic zebrafish overexpressing agrp demonstrate adipocyte hypertrophy and increased linear growth, leading to an obese phenotype [50]. Additionally, in a zebrafish model, Mrap2a/Mrap2b can not only interact with Mc4r to regulate appetite, and growth patterns, but also help to modulate the sensitivity of Mc4r to $\alpha$-MSH [47,51]. Increased food intake has also been observed in mc4r-deficient zebrafish [52].

The depletion of $\alpha$-MSH in Pomc-null mice resulted in obesity, whereas the blockade of neuronal melanocortin signaling resulted in a decrease in response to centrally administered leptin $[53,54]$. Moreover, the central administration of $\alpha-\mathrm{MSH}$ suppressed food intake and reduced BW gain in rodent models [55,56]. A deficiency of $\alpha-\mathrm{MSH}$ in a Pomc $c^{\mathrm{tm} 1 / \mathrm{tm} 1}$ mouse produced exacerbated hyperphagia and obesity when feeding with a high-fat diet 
(HFD) [12]. Our results—consistent with mouse models—showed significant increases in food intake in the $\alpha$-MSH mutants (Figure 2B,C). Because no $\alpha-\mathrm{MSH}$ peptide was produced in $\alpha$-MSH mutant fish, a significant increase in food intake was found in their larval stages (Figure 2B,C). Increased BW and obesity in adult $\alpha$-MSH mutants were also developed under regular feeding and overfeeding conditions (Figure $4 \mathrm{~A}, \mathrm{C}$ ). However, a zebrafish pomc mutant, POMCa ${ }^{141 a}$, which was also $\alpha$-MSH deficient, showed enhanced somatic growth without increasing food intake. This suggests that some aspects in addition to regulating appetite could be the key cause(s) for BW gain in our zebrafish model of POMCa ${ }^{141 a}$.

Hyperphagia alone did not promote fish growth. In medaka and zebrafish models, leptin-receptor deficiency also elicited an increased food intake pattern with a normal growth rate $[57,58]$. Because the energy homeostasis controlling system is highly complicated, simply increasing food intake might not explain the causal relationship with an acceleration of the growth rate or with weight gain [59-61]. In the Alamar Blue metabolic assay, we observed that the $\alpha$-MSH mutant decreased energy expenditure by decreasing its metabolic rate (Figure 3D). Thus, the deletion of $\alpha-\mathrm{MSH}$ in zebrafish induced hyperphagia and lower metabolism levels, which resulted in obesity. We found not only increases in food intake but also increases in the growth rate, including the standard BL, BW, and obesity, in the $\alpha$-MSH mutant fish compared with the WT controls. The growth rate was determined by energy absorption and conversion efficiency, as well as the individual metabolic rate.

We selected appetite regulatory genes that have been demonstrated to take part in regulating food intake and to serve as indicators of controlling the anorexigenic and orexigenic functions and compared their expression patterns during preprandial stages between the pomc mutant fish and WT control. We observed that the anorexigenic genes $(\operatorname{sim} 1 a, c r h b, t r h$, and $b d n f)$ were significantly downregulated in the $\alpha$-MSH mutant fish at $1.5 \mathrm{~h}$ after feeding. To further confirm the relationship between $\alpha-\mathrm{MSH}$ and appetite regulation, we used intracranial administration of an $\alpha-\mathrm{MSH}$ analog and MTII. During $1.5 \mathrm{~h}$ after administration, we discovered that fluorescence intensities were repressed significantly in the hypothalamus of both WT and $\alpha-\mathrm{MSH}$ mutant fish. Moreover, the $b d n f$ and sim $1 a$ expression levels in the $\alpha-\mathrm{MSH}^{-/-}$and $\alpha-\mathrm{MSH}$ analog/MTII administration groups were significantly enhanced compared with the WT and saline administration control groups. Lack of $\alpha$-MSH leads to suppression of anorexigenic genes expression $(b d n f, \operatorname{sim} 1 a, c r h b$, and $t r h)$ results in a reversible imbalance between food intake and energy homeostasis in $\alpha$-MSH mutant fish (Figure 7A). Most of these associated features might be regulated by $\alpha-\mathrm{MSH}[19,45]$, suggesting their critical functions in controlling metabolism observed in our $\alpha$-MSH mutant zebrafish (Figure 7B). In line with previous reports, most metabolic defects observed in fish [62], mammalian models $[4,63,64]$, and humans [65-67] have been attributed to the impairment of functional MC4R signaling in various pomc mutants. 
A

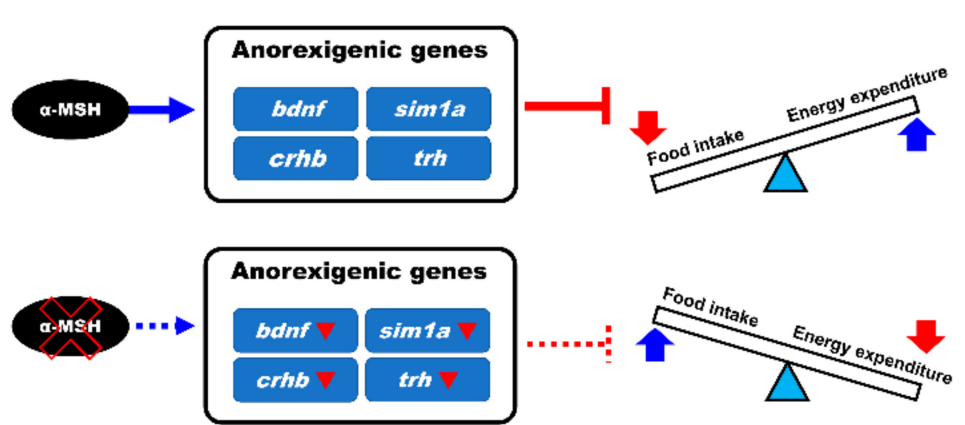

B

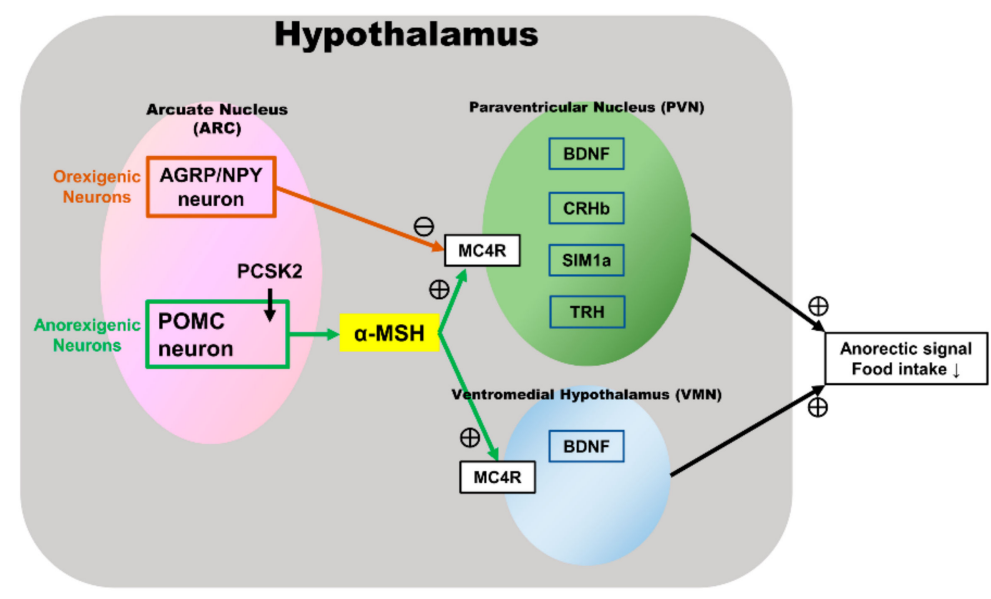

Figure 7. Anorexigenic signals in hypothalamic neural circuits promoted by $\alpha$-MSH expression in zebrafish. (A) A proposed mechanism that $\alpha$-MSH mediating food intake and energy expenditure via anorexigenic molecules manipulation which can reversed by $\alpha$-MSH depletion. (B) Schematic presentation of anorexigenic factors ( $b d n f, \operatorname{sim} 1 a, c r h b$, and $t r h)$ enhancement within the paraventricular nucleus (PVN) and the ventromedial hypothalamus (VMN) by $\alpha-\mathrm{MSH}$ resulting in a dramatic outcome with the anorexigenic phenomenon.

\section{Conclusions}

Together with the above findings in our study, the BW gain (or obesity) and increase in body lipid contents were associated with increased appetite and decreased energy expenditure rates in this zebrafish model. In summary, we characterized a critical role for melanocortin signaling for appetite suppression. Therefore, our findings may help clarify underlying mechanisms between $\alpha$-MSH signaling and obesity.

Supplementary Materials: The following are available online at https: / www.mdpi.com/article/10 .3390/biomedicines9080941/s1, Table S1: Primer sequences used for quantitative RT-PCR, Table S2: Primer sequences used for in situ hybridization probes.

Author Contributions: G.M.H. and Y.-W.T. designed the experiments, and Y.-W.H. wrote the manuscript. Y.-W.T. performed the majority of the experiments presented in this paper. Y.-W.H., H.-H.L., C.-Y.L. (Chi-Yu Lai), and C.-Y.L. (Chiu-Ya Lin) designed and performed the zebrafish experiments. All authors have read and agreed to the published version of the manuscript.

Funding: This study was supported by the Ministry of Science and Technology, Taiwan grants (MOST 108-2313-B-010-001-MY3) to Guor Mour Her. Chang Chung Memorial Hospital grants (CMRPG2I0071, CMRPG2I0072, and CMRPG2I0073) to Yi-Wen Tsai.

Institutional Review Board Statement: This study was carried out in animal experiments under approved guidelines (Approval ID: 1070708) by the Institutional Animal Care and Use Committee of National Yang Ming Chiao Tung University, Taipei 112, Taiwan.

Data Availability Statement: The data presented in this study are available upon request from the corresponding author. 
Conflicts of Interest: The authors declare no conflict of interest.

\section{References}

1. Zhang, C.; Forlano, P.M.; Cone, R.D. AgRP and POMC neurons are hypophysiotropic and coordinately regulate multiple endocrine axes in a larval teleost. Cell Metab. 2012, 15, 256-264. [CrossRef] [PubMed]

2. Gonzalez-Nunez, V.; Gonzalez-Sarmiento, R.; Rodriguez, R.E. Identification of two proopiomelanocortin genes in zebrafish (Danio rerio). Mol. Brain Res. 2003, 120, 1-8. [CrossRef]

3. Wang, L.; Sui, L.; Panigrahi, S.K.; Meece, K.; Xin, Y.; Kim, J.; Gromada, J.; Doege, C.A.; Wardlaw, S.L.; Egli, D.; et al. PC1/3 Deficiency Impacts Pro-opiomelanocortin Processing in Human Embryonic Stem Cell-Derived Hypothalamic Neurons. Stem Cell Rep. 2017, 8, 264-277. [CrossRef] [PubMed]

4. Fisher, S.L.; Yagaloff, K.A.; Burn, P. Melanocortin-4 receptor: A novel signalling pathway involved in body weight regulation. Int. J. Obes. Relat. Metab. Disord. 1999, 23, 54-58. [CrossRef]

5. Kuhnen, P.; Krude, H.; Biebermann, H. Melanocortin-4 Receptor Signalling: Importance for Weight Regulation and Obesity Treatment. Trends Mol. Med. 2019, 25, 136-148. [CrossRef]

6. Yaswen, L.; Diehl, N.; Brennan, M.B.; Hochgeschwender, U. Obesity in the mouse model of pro-opiomelanocortin deficiency responds to peripheral melanocortin. Nat. Med. 1999, 5, 1066-1070. [CrossRef]

7. Huszar, D.; Lynch, C.A.; Fairchild-Huntress, V.; Dunmore, J.H.; Fang, Q.; Berkemeier, L.R.; Gu, W.; Kesterson, R.A.; Boston, B.A.; Cone, R.D.; et al. Targeted disruption of the melanocortin-4 receptor results in obesity in mice. Cell 1997, 88, 131-141. [CrossRef]

8. Krashes, M.J.; Lowell, B.B.; Garfield, A.S. Melanocortin-4 receptor-regulated energy homeostasis. Nat. Neurosci. 2016, 19, 206-219. [CrossRef]

9. Tung, Y.C.; Piper, S.J.; Yeung, D.; O'Rahilly, S.; Coll, A.P. A comparative study of the central effects of specific proopiomelancortin (POMC)-derived melanocortin peptides on food intake and body weight in pomc null mice. Endocrinology 2006, 147, 5940-5947. [CrossRef]

10. Honda, K.; Saneyasu, T.; Hasegawa, S.; Kamisoyama, H. A comparative study of the central effects of melanocortin peptides on food intake in broiler and layer chicks. Peptides 2012, 37, 13-17. [CrossRef]

11. Lu, D.; Willard, D.; Patel, I.R.; Kadwell, S.; Overton, L.; Kost, T.; Luther, M.; Chen, W.; Woychik, R.P.; Wilkison, W.O.; et al. Agouti protein is an antagonist of the melanocyte-stimulating-hormone receptor. Nature 1994, 371, 799-802. [CrossRef] [PubMed]

12. Mountjoy, K.G.; Caron, A.; Hubbard, K.; Shome, A.; Grey, A.C.; Sun, B.; Bould, S.; Middleditch, M.; Pontre, B.; McGregor, A.; et al. Desacetyl-alpha-melanocyte stimulating hormone and alpha-melanocyte stimulating hormone are required to regulate energy balance. Mol. Metab. 2018, 9, 207-216. [CrossRef]

13. Hubbard, K.; Shome, A.; Sun, B.; Pontre, B.; McGregor, A.; Mountjoy, K.G. Chronic High-Fat Diet Exacerbates Sexually Dimorphic Pomctm1/tm1 Mouse Obesity. Endocrinology 2019, 160, 1081-1096. [CrossRef]

14. Mankowska, M.; Krzeminska, P.; Graczyk, M.; Switonski, M. Confirmation that a deletion in the POMC gene is associated with body weight of Labrador Retriever dogs. Res. Vet. Sci. 2017, 112, 116-118. [CrossRef]

15. Mayer, J.P.; Hsiung, H.M.; Flora, D.B.; Edwards, P.; Smith, D.P.; Zhang, X.Y.; Gadski, R.A.; Heiman, M.L.; Hertel, J.L.; Emmerson, P.J.; et al. Discovery of a beta-MSH-derived MC-4R selective agonist. J. Med. Chem. 2005, 48, 3095-3098. [CrossRef] [PubMed]

16. Harrold, J.A.; Williams, G. Melanocortin-4 receptors, beta-MSH and leptin: Key elements in the satiety pathway. Peptides 2006, 27, 365-371. [CrossRef]

17. Shome, A.; McGregor, A.; Cavadino, A.; Mountjoy, K.G. Central administration of beta-MSH reduces body weight in obese male Pomc(tm1/tm1) mice. Biochim. Biophys. Acta Gen. Subj. 2020, 1864, 129673. [CrossRef]

18. Appleyard, S.M.; Hayward, M.; Young, J.I.; Butler, A.A.; Cone, R.D.; Rubinstein, M.; Low, M.J. A role for the endogenous opioid beta-endorphin in energy homeostasis. Endocrinology 2003, 144, 1753-1760. [CrossRef] [PubMed]

19. Dutia, R.; Meece, K.; Dighe, S.; Kim, A.J.; Wardlaw, S.L. $\beta$-Endorphin antagonizes the effects of alpha-MSH on food intake and body weight. Endocrinology 2012, 153, 4246-4255. [CrossRef]

20. Raffan, E.; Dennis, R.J.; O’Donovan, C.J.; Becker, J.M.; Scott, R.A.; Smith, S.P.; Withers, D.J.; Wood, C.J.; Conci, E.; Clements, D.N.; et al. A Deletion in the Canine POMC Gene Is Associated with Weight and Appetite in Obesity-Prone Labrador Retriever Dogs. Cell Metab. 2016, 23, 893-900. [CrossRef] [PubMed]

21. Dubern, B.; Lubrano-Berthelier, C.; Mencarelli, M.; Ersoy, B.; Frelut, M.L.; Bougle, D.; Costes, B.; Simon, C.; Tounian, P.; Vaisse, C.; et al. Mutational analysis of the pro-opiomelanocortin gene in French obese children led to the identification of a novel deleterious heterozygous mutation located in the alpha-melanocyte stimulating hormone domain. Pediatr. Res. 2008, 63, 211-216. [CrossRef] [PubMed]

22. Samuels, M.E.; Gallo-Payet, N.; Pinard, S.; Hasselmann, C.; Magne, F.; Patry, L.; Chouinard, L.; Schwartzentruber, J.; Rene, P.; Sawyer, N.; et al. Bioinactive ACTH causing glucocorticoid deficiency. J. Clin. Endocrinol. Metab. 2013, 98, 736-742. [CrossRef] [PubMed]

23. Santoro, N.; Cirillo, G.; Xiang, Z.; Tanas, R.; Greggio, N.; Morino, G.; Iughetti, L.; Vottero, A.; Salvatoni, A.; Di Pietro, M.; et al. Prevalence of pathogenetic MC4R mutations in Italian children with early onset obesity, tall stature and familial history of obesity. BMC Med. Genet. 2009, 10, 25. [CrossRef] [PubMed]

24. Farooqi, I.S.; Yeo, G.S.; Keogh, J.M.; Aminian, S.; Jebb, S.A.; Butler, G.; Cheetham, T.; O'Rahilly, S. Dominant and recessive inheritance of morbid obesity associated with melanocortin 4 receptor deficiency. J. Clin. Investig. 2000, 106, 271-279. [CrossRef] 
25. Yeo, G.S.; Farooqi, I.S.; Challis, B.G.; Jackson, R.S.; O'Rahilly, S. The role of melanocortin signalling in the control of body weight: Evidence from human and murine genetic models. QJM Int. J. Med. 2000, 93, 7-14. [CrossRef] [PubMed]

26. Krude, H.; Gruters, A. Implications of proopiomelanocortin (POMC) mutations in humans: The POMC deficiency syndrome. Trends Endocrinol. Metab. 2000, 11, 15-22. [CrossRef]

27. Clark, A.J.; Weber, A. Adrenocorticotropin insensitivity syndromes. Endocr. Rev. 1998, 19, 828-843. [CrossRef] [PubMed]

28. Elias, L.L.; Huebner, A.; Metherell, L.A.; Canas, A.; Warne, G.L.; Bitti, M.L.; Cianfarani, S.; Clayton, P.E.; Savage, M.O.; Clark, A.J Tall stature in familial glucocorticoid deficiency. Clin. Endocrinol. 2000, 53, 423-430. [CrossRef]

29. Imamine, H.; Mizuno, H.; Sugiyama, Y.; Ohro, Y.; Sugiura, T.; Togari, H. Possible relationship between elevated plasma ACTH and tall stature in familial glucocorticoid deficiency. Tohoku J. Exp. Med. 2005, 205, 123-131. [CrossRef]

30. Hansen, I.A.; To, T.T.; Wortmann, S.; Burmester, T.; Winkler, C.; Meyer, S.R.; Neuner, C.; Fassnacht, M.; Allolio, B. The proopiomelanocortin gene of the zebrafish (Danio rerio). Biochem. Biophys. Res. Commun. 2003, 303, 1121-1128. [CrossRef]

31. To, T.T.; Hahner, S.; Nica, G.; Rohr, K.B.; Hammerschmidt, M.; Winkler, C.; Allolio, B. Pituitary-interrenal interaction in zebrafish interrenal organ development. Mol. Endocrinol. 2007, 21, 472-485. [CrossRef] [PubMed]

32. Wagle, M.; Mathur, P.; Guo, S. Corticotropin-releasing factor critical for zebrafish camouflage behavior is regulated by light and sensitive to ethanol. J. Neurosci. 2011, 31, 214-224. [CrossRef] [PubMed]

33. Dang, Y.; Wang, F.E.; Liu, C. Real-time PCR array to study the effects of chemicals on the growth hormone/insulin-like growth factors (GH/IGFs) axis of zebrafish embryos/larvae. Chemosphere 2018, 207, 365-376. [CrossRef]

34. Jowett, T. Double in situ hybridization techniques in zebrafish. Methods 2001, 23, 345-358. [CrossRef] [PubMed]

35. Shimada, Y.; Hirano, M.; Nishimura, Y.; Tanaka, T. A high-throughput fluorescence-based assay system for appetite-regulating gene and drug screening. PLoS ONE 2012, 7, e52549. [CrossRef]

36. Lai, C.Y.; Yeh, K.Y.; Lin, C.Y.; Hsieh, Y.W.; Lai, H.H.; Chen, J.R.; Hsu, C.C.; Her, G.M. MicroRNA-21 Plays Multiple Oncometabolic Roles in the Process of NAFLD-Related Hepatocellular Carcinoma via PI3K/AKT, TGF-beta, and STAT3 Signaling. Cancers 2021, 13, 940. [CrossRef] [PubMed]

37. Lai, C.Y.; Lin, C.Y.; Hsu, C.C.; Yeh, K.Y.; Her, G.M. Liver-directed microRNA-7a depletion induces nonalcoholic fatty liver disease by stabilizing YY1-mediated lipogenic pathways in zebrafish. Biochim. Biophys. Acta Mol. Cell Biol. Lipids 2018, 1863, 844-856. [CrossRef]

38. Renquist, B.J.; Zhang, C.; Williams, S.Y.; Cone, R.D. Development of an assay for high-throughput energy expenditure monitoring in the zebrafish. Zebrafish 2013, 10, 343-352. [CrossRef]

39. Montalbano, G.; Mania, M.; Guerrera, M.C.; Abbate, F.; Laura, R.; Navarra, M.; Vega, J.A.; Ciriaco, E.; Germana, A. Morphological differences in adipose tissue and changes in BDNF/Trkb expression in brain and gut of a diet induced obese zebrafish model. Ann. Anat. 2016, 204, 36-44. [CrossRef] [PubMed]

40. Reinecke, M.; Bjornsson, B.T.; Dickhoff, W.W.; McCormick, S.D.; Navarro, I.; Power, D.M.; Gutierrez, J. Growth hormone and insulin-like growth factors in fish: Where we are and where to go. Gen. Comp. Endocrinol. 2005, 142, 20-24. [CrossRef] [PubMed]

41. Reinecke, M. Influences of the environment on the endocrine and paracrine fish growth hormone-insulin-like growth factor-I system. J. Fish Biol. 2010, 76, 1233-1254. [CrossRef]

42. Yokobori, E.; Azuma, M.; Nishiguchi, R.; Kang, K.S.; Kamijo, M.; Uchiyama, M.; Matsuda, K. Neuropeptide Y stimulates food intake in the Zebrafish, Danio rerio. J. Neuroendocrinol. 2012, 24, 766-773. [CrossRef]

43. Sundarrajan, L.; Unniappan, S. Small interfering RNA mediated knockdown of irisin suppresses food intake and modulates appetite regulatory peptides in zebrafish. Gen. Comp. Endocrinol. 2017, 252, 200-208. [CrossRef]

44. Zheng, B.; Li, S.; Liu, Y.; Li, Y.; Chen, H.; Tang, H.; Liu, X.; Lin, H.; Zhang, Y.; Cheng, C.H.K. Spexin Suppress Food Intake in Zebrafish: Evidence from Gene Knockout Study. Sci. Rep. 2017, 7, 14643. [CrossRef]

45. Kirwan, P.; Kay, R.G.; Brouwers, B.; Herranz-Perez, V.; Jura, M.; Larraufie, P.; Jerber, J.; Pembroke, J.; Bartels, T.; White, A.; et al. Quantitative mass spectrometry for human melanocortin peptides in vitro and in vivo suggests prominent roles for beta-MSH and desacetyl alpha-MSH in energy homeostasis. Mol. Metab. 2018, 17, 82-97. [CrossRef] [PubMed]

46. Cerda-Reverter, J.M.; Schioth, H.B.; Peter, R.E. The central melanocortin system regulates food intake in goldfish. Regul. Pept. 2003, 115, 101-113. [CrossRef]

47. Agulleiro, M.J.; Cortes, R.; Fernandez-Duran, B.; Navarro, S.; Guillot, R.; Meimaridou, E.; Clark, A.J.; Cerda-Reverter, J.M. Melanocortin 4 receptor becomes an ACTH receptor by coexpression of melanocortin receptor accessory protein 2 . Mol. Endocrinol. 2013, 27, 1934-1945. [CrossRef] [PubMed]

48. Zhang, K.Q.; Hou, Z.S.; Wen, H.S.; Li, Y.; Qi, X.; Li, W.J.; Tao, Y.X. Melanocortin-4 Receptor in Spotted Sea Bass, Lateolabrax maculatus: Cloning, Tissue Distribution, Physiology, and Pharmacology. Front. Endocrinol. 2019, 10, 705. [CrossRef] [PubMed]

49. White, S.L.; Volkoff, H.; Devlin, R.H. Regulation of feeding behavior and food intake by appetite-regulating peptides in wild-type and growth hormone-transgenic coho salmon. Horm. Behav. 2016, 84, 18-28. [CrossRef]

50. Song, Y.; Cone, R.D. Creation of a genetic model of obesity in a teleost. Fed. Am. Soc. Exp. Biol. J. 2007, 21, 2042-2049. [CrossRef]

51. Sebag, J.A.; Zhang, C.; Hinkle, P.M.; Bradshaw, A.M.; Cone, R.D. Developmental control of the melanocortin-4 receptor by MRAP2 proteins in zebrafish. Science 2013, 341, 278-281. [CrossRef] [PubMed]

52. Fei, F.; Sun, S.Y.; Yao, Y.X.; Wang, X. Generation and phenotype analysis of zebrafish mutations of obesity-related genes lepr and mc4r. Sheng Li Xue Bao 2017, 69, 61-69. [PubMed] 
53. Schwartz, M.W.; Woods, S.C.; Porte, D., Jr.; Seeley, R.J.; Baskin, D.G. Central nervous system control of food intake. Nature 2000, 404, 661-671. [CrossRef]

54. Morton, G.J.; Cummings, D.E.; Baskin, D.G.; Barsh, G.S.; Schwartz, M.W. Central nervous system control of food intake and body weight. Nature 2006, 443, 289-295. [CrossRef] [PubMed]

55. McMinn, J.E.; Wilkinson, C.W.; Havel, P.J.; Woods, S.C.; Schwartz, M.W. Effect of intracerebroventricular alpha-MSH on food intake, adiposity, c-Fos induction, and neuropeptide expression. Am. J. Physiol. Regul. Integr. Comp. Physiol. 2000, 279, R695-R703. [CrossRef]

56. Eerola, K.; Nordlund, W.; Virtanen, S.; Dickens, A.M.; Mattila, M.; Ruohonen, S.T.; Chua, S.C., Jr.; Wardlaw, S.L.; Savontaus, M.; Savontaus, E. Lentivirus-mediated alpha-melanocyte-stimulating hormone overexpression in the hypothalamus decreases diet induced obesity in mice. J. Neuroendocrinol. 2013, 25, 1298-1307. [CrossRef]

57. Chisada, S.; Kurokawa, T.; Murashita, K.; Ronnestad, I.; Taniguchi, Y.; Toyoda, A.; Sakaki, Y.; Takeda, S.; Yoshiura, Y. Leptin receptor-deficient (knockout) medaka, Oryzias latipes, show chronical up-regulated levels of orexigenic neuropeptides, elevated food intake and stage specific effects on growth and fat allocation. Gen. Comp. Endocrinol. 2014, 195, 9-20. [CrossRef]

58. Ahi, E.P.; Brunel, M.; Tsakoumis, E.; Schmitz, M. Transcriptional study of appetite regulating genes in the brain of zebrafish (Danio rerio) with impaired leptin signalling. Sci. Rep. 2019, 9, 20166. [CrossRef]

59. Hollis, J.H. The effect of mastication on food intake, satiety and body weight. Physiol. Behav. 2018, 193, 242-245. [CrossRef]

60. Luo, Y.; Zhang, X.; Tsauo, J.; Jung, H.Y.; Song, H.Y.; Zhao, H.; Li, J.; Gong, T.; Song, P.; Li, X. Intragastric satiety-inducing device reduces food intake and suppresses body weight gain in a rodent model. Surg. Endosc. 2020, 35, 1052-1057. [CrossRef]

61. Santiago-Garcia, P.A.; Lopez, M.G. Agavins from Agave angustifolia and Agave potatorum affect food intake, body weight gain and satiety-related hormones (GLP-1 and ghrelin) in mice. Food Funct. 2014, 5, 3311-3319. [CrossRef]

62. Liu, T.; Deng, Y.; Zhang, Z.; Cao, B.; Li, J.; Sun, C.; Hu, Z.; Zhang, J.; Li, J.; Wang, Y. Melanocortin Receptor 4 (MC4R) Signaling System in Nile Tilapia. Int. J. Mol. Sci. 2020, 21, 7036. [CrossRef]

63. Mastinu, A.; Premoli, M.; Maccarinelli, G.; Grilli, M.; Memo, M.; Bonini, S.A. Melanocortin 4 receptor stimulation improves social deficits in mice through oxytocin pathway. Neuropharmacology 2018, 133, 366-374. [CrossRef]

64. Cui, H.; Sohn, J.W.; Gautron, L.; Funahashi, H.; Williams, K.W.; Elmquist, J.K.; Lutter, M. Neuroanatomy of melanocortin-4 receptor pathway in the lateral hypothalamic area. J. Comp. Neurol. 2012, 520, 4168-4183. [CrossRef] [PubMed]

65. Lotta, L.A.; Mokrosinski, J.; de Oliveira, E.M.; Li, C.; Sharp, S.J.; Luan, J.; Brouwers, B.; Ayinampudi, V.; Bowker, N.; Kerrison, N.; et al. Human Gain-of-Function MC4R Variants Show Signaling Bias and Protect against Obesity. Cell 2019, 177, 597-607. [CrossRef] [PubMed]

66. Ayers, K.L.; Glicksberg, B.S.; Garfield, A.S.; Longerich, S.; White, J.A.; Yang, P.; Du, L.; Chittenden, T.W.; Gulcher, J.R.; Roy, S.; et al. Melanocortin 4 Receptor Pathway Dysfunction in Obesity: Patient Stratification Aimed at MC4R Agonist Treatment. J. Clin. Endocrinol. Metab. 2018, 103, 2601-2612. [CrossRef] [PubMed]

67. Eneli, I.; Xu, J.; Webster, M.; McCagg, A.; Van Der Ploeg, L.; Garfield, A.S.; Estrada, E. Tracing the effect of the melanocortin4 receptor pathway in obesity: Study design and methodology of the TEMPO registry. Appl. Clin. Genet. 2019, 12, 87-93. [CrossRef] [PubMed] 